\title{
Do endogenous opioids and nitric oxide participate in the anticonvulsant action of dipyrone?
}

G.M.L. Reis ${ }^{1}$, M.C. Doretto ${ }^{2}$, I.D.G. Duarte ${ }^{1}$ and M.A.K.F. Tatsuo ${ }^{1}$

\author{
Departamentos de ${ }^{1}$ Farmacologia and ${ }^{2}$ Fisiologia e Biofísica, \\ Instituto de Ciências Biológicas, Universidade Federal de Minas Gerais, \\ Belo Horizonte, MG, Brasil
}

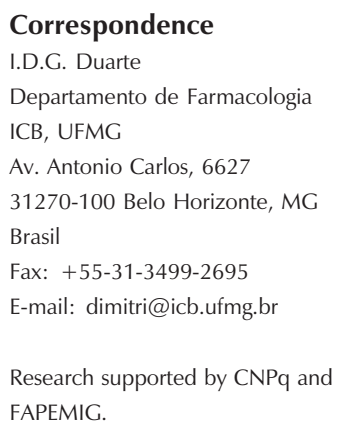

\begin{abstract}
It was previously reported that systemic administration of dipyrone inhibited the tonic component of generalized tonic-clonic seizures in both the electroshock and the audiogenic seizure models. The aim of the present study was to investigate the mechanisms involved in the anticonvulsant action of dipyrone by assessing the role of nitric oxide and opioids in the electroshock (female 60- to 90-day-old Wistar rats, $\mathrm{N}=5-11$ ) and audiogenic seizure (female 60- to 90-day-old Wistar audiogenic rats, $\mathrm{N}=5-11)$ models of epilepsy. Naloxone $(5 \mathrm{mg} / \mathrm{kg}, s c)$ significantly reversed the anticonvulsant effect of dipyrone in rats submitted to the induction of audiogenic seizures (ANOVA/Bonferroni's test), suggesting the involvement of opioid peptides in this action. In the electroshock model no reversal of the anticonvulsant effect of dipyrone by naloxone $(5 \mathrm{mg} / \mathrm{kg}, s c)$ was demonstrable. The acute $(120 \mathrm{mg} / \mathrm{kg}$, ip) and chronic ( $25 \mathrm{mg} / \mathrm{kg}$, ip, twice a day/4 days) administration of L-NOARG did not reverse the anticonvulsant action of dipyrone in the audiogenic seizure model, suggesting that the nitric oxide pathway does not participate in such effect. Indomethacin (10, 20 and $30 \mathrm{mg} / \mathrm{kg}$, ip) used for comparison had no anticonvulsant effect in the audiogenic seizure model. In conclusion, opioid peptides but not nitric oxide seem to be involved in the anticonvulsant action of dipyrone in audiogenic seizures.
\end{abstract}

\section{Introduction}

Dipyrone, a substance belonging to the group of nonsteroidal anti-inflammatory drugs (NSAIDs), possesses analgesic, antipyretic and anti-inflammatory activities. Initially, analgesia by NSAIDs was explained by an inhibitory action on prostaglandin synthesis $(1,2)$. Despite the numerous behavioral and electrophysiological studies performed thus far, the mode and site of action of dipy-
Key words

- Epilepsy

- Dipyrone

- Audiogenic seizures

- Electroshock

- Nitric oxide

- Opiates (1) $\ldots \ldots \ldots \ldots \ldots \ldots$ rone remain controversial. Nikolova et al. (3) suggested that the profile of the pharmacological effects of dipyrone is certainly different from those of other NSAIDs.

Lorenzetti and Ferreira (4) have reported that the peripheral analgesic effect of dipyrone may result from direct blockade of hyperalgesia rather than from prevention of the release of prostaglandins in inflamed tissues. Results reported by Carlsson et al. (5) indicated that dipyrone induces an antinocicep- 
tive effect both by peripheral and central mechanisms.

Activation of the L-arginine-nitric oxide (NO)-cGMP pathway seems to contribute to the antinociceptive activity of dipyrone at the spinal and peripheral levels. It was observed that the antinociceptive effect induced by intraplantar (6), intraperitoneal and intrathecal (7) administration of dipyrone was abolished by pretreatment with $\mathrm{N}^{\mathrm{G}}$-monomethyl-L-arginine acetate, an NO synthase inhibitor, or by methylene blue, an inhibitor of soluble guanylate cyclase.

It has also been suggested that endogenous opioids may be involved in the induction of the central antinociceptive effect of dipyrone $(8,9)$.

Doretto et al. (10) reported that dipyrone exhibited an anticonvulsant action in electroshock, acute audiogenic seizure and audiogenic kindling models of experimental epilepsy. Conversely, indomethacin, diclofenac and aspirin, tested only in the electroshock model, did not show any effect. On the other hand, some studies have reported that aspirin elicits protection against pentylenetetrazole seizures (11) and that ibuprofen and piroxicam enhance the anticonvulsive activity of diphenylhydantoin (12).

The aim of the present study was to investigate the mechanisms by which dipyrone exerts its anticonvulsant action by evaluating the role of prostaglandins, NO and opioids. For this purpose, indomethacin, a prototype of NSAIDs, the NO synthase inhibitor $\mathrm{N}^{\omega}$-nitro-L-arginine (L-NOARG), and the opioid antagonist naloxone were used.

\section{Material and Methods}

\section{Animals}

Naive 60-90-year-old female Wistar rats (200-250 g) were used for electroshock experiments. For audiogenic seizures, genetically susceptible female animals (60-90 days old) were taken from our own colony of
Wistar audiogenic rats, currently bred at the animal facilities of the Physiology and Biophysics Department at the Institute of Biological Sciences, Federal University of Minas Gerais, Brazil $(10,13)$. In both groups, animals were housed 5 per cage and kept at $24^{\circ} \mathrm{C}$ with free access to food and water under a 12-h artificial light/dark cycle.

\section{Induction and behavioral evaluation of seizures}

All experiments reported in this study were approved by the Ethics Committee on Animal Experimentation (CETEA/UFMG protocol No. 02/02).

\section{Audiogenic seizures}

All Wistar audiogenic rats were submitted to three sound stimuli at 70,74 and 78 days of age in order to determine audiogenic seizure susceptibility. The testing apparatus consisted of a $32 \times 36 \times 32 \mathrm{~cm}$ metal cage placed inside a larger, soundproof box, both provided with doors and frontal glass windows. Animals were observed for $1 \mathrm{~min}$ before stimulation. The sound stimulus was provided by an electric door bell recorded on an audiotape $(120 \mathrm{~dB})$ and was delivered in the acoustic chamber through a loudspeaker placed on the back wall of the larger box until tonic seizures appeared or during a maximum of $1 \mathrm{~min}$.

Behavior was assessed by direct and systematic observation using a set of discrete behavioral categories, most commonly observed in the test situation. A severity index (SI) was calculated as previously described $(14,15)$. Briefly, the index includes a graded linear scale which determines a range of severity from $\mathrm{SI}=0.00$ to $\mathrm{SI}=1.0$ (maximum). The most frequent behavioral sequences correspond to SI of the following values: $\mathrm{SI}=0.00$ - no seizures; $\mathrm{SI}=0.11$ wild running with only one running fit; SI = 0.23 - wild running with only one running fit, 
jumping and atonic falling; $\mathrm{SI}=0.38$ - wild running with two running fits, jumping and atonic falling; $\mathrm{SI}=0.61$ - all of the above plus tonic convulsion (back arching tonus); $\mathrm{SI}=0.73$ - all of the above plus partial (only forelimb or hind limb) and generalized (forelimb and hind limb) clonic seizures; SI = 0.85 - all of the above plus clonic spasms; $\mathrm{SI}=0.90$ - all of the above plus head ventral flexion; SI $=0.95$ - all of the above plus forelimb hyperextension; SI $=1.0$ - all of the above plus forelimb and hind limb hyperextension. The SI values represent a modified version of a previously described equation (16).

All susceptible animals used in these experiments displayed an SI $\geq 0.85$ at the beginning of the studies, at least generalized tonic-clonic seizures followed by clonic spasms in all three screening tests. Results are reported as the mean \pm SEM of three screening tests. For the purposes of this study, blockade of the audiogenic seizures by dipyrone was considered to be the absence of tonic convulsion (SI <0.61) and reversal of the dipyrone anticonvulsant effect was considered to be the recovery of the tonic component of seizures ( $\mathrm{SI} \geq 0.61$ ).

\section{Electroshock-induced seizures}

In the electroshock-induced seizures, the same electric stimulus (70 mA, $60 \mathrm{~Hz}$ ) was used for all animals, produced by an Elektroshockgerät apparatus (Karl Kolbe, Scientific Technical Supplies, Frankfurt, Germany). The stimulus was applied over a period of $1 \mathrm{~s}$ through a pair of ear clip electrodes. The behavioral evaluation was based on an electroshock score, taking into account the severity of the tonic component of the seizure, using a four-point scale as follows: $0=$ no seizure; $1=$ forelimb extension without hind limb extension; $2=$ complete forelimb extension and partial hind limb extension; $3=$ complete forelimb and hind limb extension, parallel to the tail.

\section{Drugs}

All drugs were purchased from Sigma (St. Louis, MO, USA) and were dissolved in $0.9 \% \mathrm{NaCl}$ solution. Dipyrone $(300 \mathrm{mg} / \mathrm{kg}$, ip) and indomethacin (10, 20 and $30 \mathrm{mg} / \mathrm{kg}$, ip) were injected $30 \mathrm{~min}$ before the seizureinducing stimuli. Naloxone $(5 \mathrm{mg} / \mathrm{kg}, s c)$ was injected 40 min before the seizure-inducing stimuli. L-NOARG was injected 35 min before sound stimulation at the dose of $120 \mathrm{mg} / \mathrm{kg}$, ip. Animals chronically treated with L-NOARG $(25 \mathrm{mg} / \mathrm{kg}$, ip, twice a day $/ 4$ days) received sound stimulation $35 \mathrm{~min}$ after the last injection.

\section{Statistical analysis}

Data were analyzed statistically by oneway analysis of variance (ANOVA) with the post hoc Bonferroni's test for multiple comparisons. Probabilities lower than 5\% ( $\mathrm{P}<$ $0.05)$ were considered to be statistically significant.

\section{Results}

\section{Anticonvulsant action of dipyrone}

In the electroshock-induced seizures all Wistar rats treated with the same dose of dipyrone (300 mg/kg, ip) displayed score 1 (only forelimb extension) compared to animals receiving $0.9 \% \mathrm{NaCl}$, which displayed score 3 (complete forelimb and hind limb extension). Wistar audiogenic rats also exhibited a reduction of seizure severity from $0.94 \pm 0.06$ in the saline-treated group to $0.22 \pm 0.12$ in the dipyrone-treated group. Dose and time were determined in pilot experiments. These results are illustrated in Figure $1(\mathrm{~N}=5-11)$.

\section{Effect of naloxone on the anticonvulsant action of dipyrone}

Naloxone at $5 \mathrm{mg} / \mathrm{kg}$, sc (Figure 2A, 
Figure 1. Anticonvulsant effect of dipyrone on audiogenic seizures (AS, panel A) and electroshock-induced seizures (ES, panel B). Dipyrone (Dip; 300 mg/ $\mathrm{kg}$, ip) blocked the tonic component of seizures in both AS and ES. Dipyrone was administered 30 min before the seizure-inducing stimuli in female Wistar audiogenic rats in AS or female Wistar rats in ES. Data are reported as mean \pm SEM severity index or mean ES score $(\mathrm{N}=5$ 11). ${ }^{*} P<0.05$ compared to the saline (Sal)-treated group (ANOVA + Bonferroni's test).
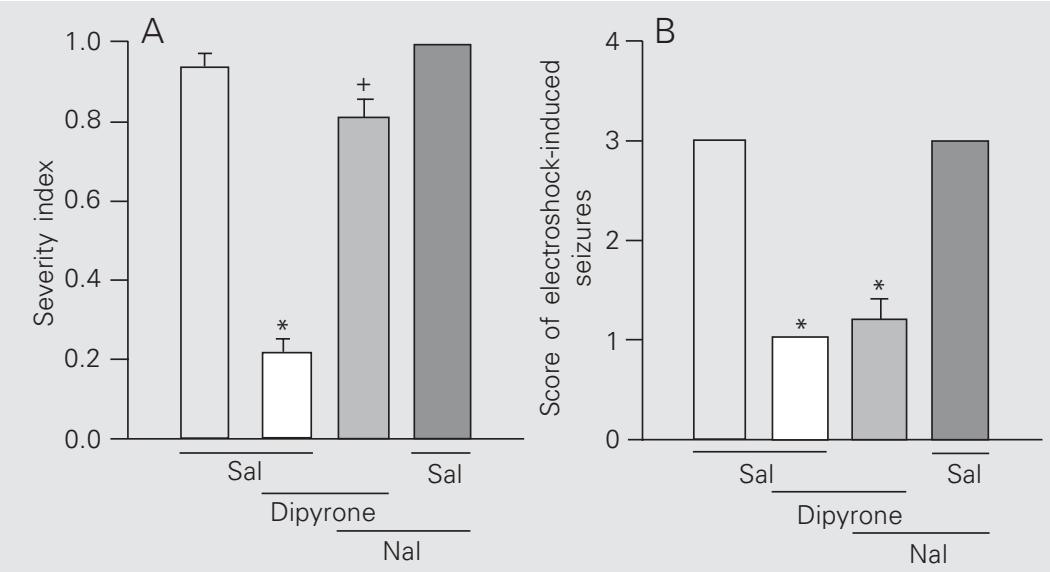

Figure 2. Effect of naloxone on the anticonvulsant action of dipyrone. $A$, In the audiogenic seizure model, naloxone (5 mg/kg, sc) reversed the anticonvulsant action of dipyrone (300 $\mathrm{mg} / \mathrm{kg}, i p)$. $B$, In the electroshock-induced seizure model naloxone $(5 \mathrm{mg} / \mathrm{kg}, \mathrm{sc}$ ) did not reverse the anticonvulsant effect of dipyrone. Naloxone (Nal) was administered $10 \mathrm{~min}$ before dipyrone. Data are reported as mean \pm SEM severity index or electroshock score $(\mathrm{N}$ $=5-11) .{ }^{*} P<0.05$ compared to the saline (Sal)-treated group and $+P<0.05$ compared to the dipyrone-treated group (ANOVA + Bonferroni's test).
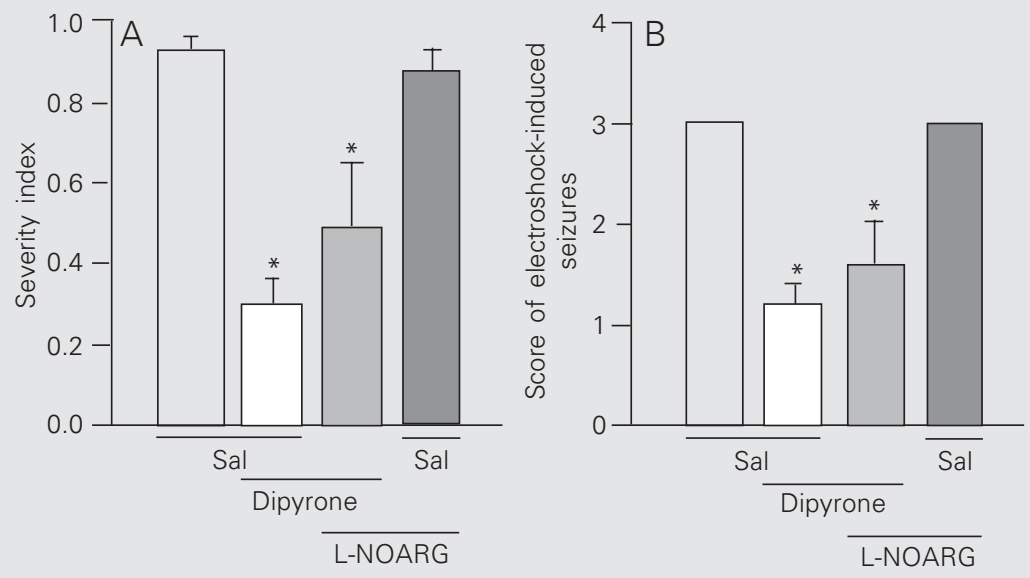

Figure 3. Effect of acute administration of $\mathrm{N}^{\omega}$-nitro-L-arginine (L-NOARG) on the anticonvulsant action of dipyrone in audiogenic seizures (A) and electroshock (B). L-NOARG $(120 \mathrm{mg} / \mathrm{kg}$, ip) administered 5 min before dipyrone did not reverse the anticonvulsant effect of dipyrone (300 mg/kg, ip). Data are reported as mean \pm SEM severity index or electroshock score ( $N=$ 5-6). ${ }^{*} P<0.05$ compared to the saline (Sal)-treated group (ANOVA + Bonferroni's test)
$\mathrm{N}=5-11)$ reversed the anticonvulsant effect of dipyrone $(300 \mathrm{mg} / \mathrm{kg}$, ip $)$ in female Wistar audiogenic rats $(\mathrm{P}<0.05$, ANOVA + Bonferroni's test). In contrast, in Wistar rats submitted to electroshock-induced seizures no reversal of the anticonvulsant effect of dipyrone by naloxone at a dose of $5 \mathrm{mg} / \mathrm{kg}$ was seen (Figure $2 \mathrm{~B}, \mathrm{~N}=5-11$ ), even at higher doses (data not shown). Naloxone did not have an anticonvulsant effect per se.

\section{Effect of L-NOARG on the anticonvulsant action of dipyrone}

Acute treatment with L-NOARG (120 $\mathrm{mg} / \mathrm{kg}$, ip) did not reverse the anticonvulsant effect of dipyrone $(300 \mathrm{mg} / \mathrm{kg}$, ip) in female Wistar audiogenic rats (Figure 3A, N = 5-6) and in the electroshock model (Figure 3B, $\mathrm{N}=5$ ). L-NOARG had no anticonvulsant effect per se. Chronic administration of LNOARG ( $25 \mathrm{mg} / \mathrm{kg}$ twice a day/4 days) also did not have an antagonistic effect (data not shown).

\section{Effect of indomethacin on audiogenic seizures}

Indomethacin was administered to Wistar audiogenic rats $(\mathrm{N}=5) 30 \mathrm{~min}$ before sound stimulation at doses of 10,20 and $30 \mathrm{mg} / \mathrm{kg}$, ip. However, the tonic component of audiogenic seizures was not blocked (data not shown).

\section{Discussion}

The present experiments show that dipyrone has anticonvulsant effects in the electroshock and audiogenic seizure models. Wahnschaffe and Loscher (17) showed that natural changes in sex hormone levels during the estrous cycle in rats do not affect seizure severity or development. Since our results using female rats were slightly more intense than those obtained with males (data not shown), we used only female rats in all 
experiments. Dipyrone $(300 \mathrm{mg} / \mathrm{kg}$, ip $)$ did not affect the motor response of the animals. We previously observed that dipyrone is also active against pentylenetetrazole seizures (Magalhaes LH, Doretto MC and Moraes MF, unpublished results). The dose of dipyrone used was that with a maximal effect and was obtained from a previously constructed dose-response curve (10).

In the presence of naloxone, which is an opioid receptor antagonist, the anticonvulsant action of dipyrone in female Wistar audiogenic rats was not demonstrable, suggesting an interaction with the opioidergic system, probably via opiate receptors. In the electroshock model, the reversal of the anticonvulsant effect of dipyrone by naloxone was not observed. The dose of naloxone used was the same as that used by Coimbra et al. (18). Using the same kind of seizures in BALB/c mice, Chen et al. (19) reported that naloxone reversed the anticonvulsant effect of morphine.

Since the L-arginine-NO-cGMP pathway seems to be involved in the antinociceptive effect of dipyrone $(6,7)$, the hypothesis of the involvement of $\mathrm{NO}$ in its anticonvulsant mechanism of action is attractive. However, our results showed that acute or chronic L-NOARG treatment did not reverse the anticonvulsant effect of dipyrone in Wistar audiogenic rats, suggesting that the NO pathway is not involved in the mechanism of anticonvulsant action of dipyrone in audiogenic seizures. Del-Bel et al. (20) reported that audiogenic seizure-resistant rats did not modify their behavior after L-NOARG-induced systemic NO synthase blockade. Also, GEPR-3s (genetically epilepsy-prone rats), Sprague-Dawley-derived rats of the so-called mild subcolony (in contrast to GEPR-9s, severe subcolony) that display audiogenic seizures when sound-stimulated $(21,22)$, did not exhibit changes in seizure severity or in the mean latencies of wild running or tonicclonic seizure after acute or chronic LNOARG treatment (23). Although it has been suggested that NO participates in several neurodegenerative conditions, including epilepsy $(24,25)$, its contribution to convulsant events is still unclear. Some available data related to NO synthase inhibition have shown a decreasing $(23,26)$ or an increasing effect on seizure susceptibility $(27,28)$.

Several studies have suggested an anticonvulsant action for endogenous prostanoids $(29,30)$. It is possible that the anticonvulsant action of dipyrone is due to its effect as a cyclooxygenase inhibitor. However, our results have shown that indomethacin, a prototype of prostaglandin synthesis inhibitor, was unable to block the tonic component of audiogenic seizures. This suggests that the anticonvulsant effect of dipyrone is not a common effect of NSAIDs. Previous results from our laboratory have shown that indomethacin, as well as diclofenac and aspirin, did not inhibit electroshock-induced seizures (10).

The results of the present study suggest that the opioidergic pathway is involved in the anticonvulsant mechanism of dipyrone in audiogenic seizures whereas the NO pathway did not seem to contribute to this effect. In the electroshock-induced seizure model, although a decrease in the severity of the tonic component had been observed, we cannot state that the opioidergic pathway participates in the anticonvulsant effect of dipyrone.

\section{References}

1. Vane JR (1971). Inhibition of prostaglandin synthesis as a mechanism of action for aspirin-like drugs. Nature New Biology, 231: 232235.

2. Ferreira SH (1973). Prostaglandins and mechanism of analgesia produced by aspirin-like drugs. British Journal of Pharmacology, 49 86-97.

3. Nikolova MD, Stefanova R, Nikolov R \& Daleva L (1980). Comparative study of dipyrone (analgin) and acetylsalicylic acid: analgesic 
effects. In: Ovtcharov R \& Pola W (Editors), Proceedings of Dipyrone Symposium. Stuttgart, Germany, 83.

4. Lorenzetti BB \& Ferreira SH (1985). Mode of analgesic action of dipyrone: direct antagonism of inflammatory hyperalgesia. European Journal of Pharmacology, 114: 375-381.

5. Carlsson KH, Helmreich J \& Jurna I (1986). Activation of inhibition from the periaqueductal grey matter mediates central analgesic effect of metamizol (dipyrone). Pain, 27: 373-390.

6. Duarte IDG, Dos Santos IR, Lorenzetti BB \& Ferreira SH (1992). Analgesia by direct antagonism of nociceptor sensitization involves the arginine-nitric-oxide-cGMP pathway. European Journal of Pharmacology, 217: 225-227.

7. Lorenzetti BB \& Ferreira SH (1996). Activation of the arginine-nitric oxide pathway in primary sensory neurons contributes to dipyroneinduced spinal and peripheral analgesia. Inflammation Research, 45: 308-311

8. Akman H, Aksu F, Gültekin I, Özbek H, Oral U, Doran F \& Baysal F (1996). A possible central antinociceptive effect of dipyrone in mice. Pharmacology, 53: 71-78.

9. Tortorici V, Vásquez E \& Vanegas H (1996). Naloxone partial reversal of the antinociception produced by dipyrone microinjected into periaqueductal gray of rats. Possible involvement of medullary offand on-cells. Brain Research, 725: 106-110.

10. Doretto MC, Garcia-Cairasco N, Pimenta NJG, Souza DA \& Tatsuo MAKF (1998). Dipyrone, a novel anticonvulsant agent? Insights from three experimental epilepsy models. NeuroReport, 9: 24152421.

11. Srivastava AK \& Gupta YK (2001). Aspirin modulates the anticonvulsant effects of diazepam and sodium valproate in pentylenetetrazole and maximal electroshock induced seizures in mice. Indian Journal of Physiology and Pharmacology, 45: 474-480.

12. Kaminski R, Kozicka M, Parada-turska J, Dziki M, Kleinrok Z, Turski WA \& Czuczwar SJ (1998). Effect of non-steroidal anti-inflammatory drugs on the anticonvulsive activity of valproate and diphenylhydantoin against maximal electroshock-induced seizures in mice. Pharmacological Research, 37: 375-381.

13. Doretto MC, Fonseca CG, Lobo RB, Terra VC, Oliveira JA \& GarciaCairasco N (2003). Quantitative study of the response to genetic selection of the Wistar audiogenic rat strain (WAR). Behavior Genetics, 33: 33-42

14. Garcia-Cairasco N \& Sabbatini RME (1983). Role of the substantia nigra in audiogenic seizures: a neuroethological analysis in the rat. Brazilian Journal of Medical and Biological Research, 16: 171-183.

15. Garcia-Cairasco N, Doretto MC, Prado PR, Jorge BPD, Terra VC \& Oliveira JAC (1992). New insights into behavioral evaluation of audiogenic seizures. A comparison of two ethological methods. Behavioural Brain Research, 48: 49-56.
16. Garcia-Cairasco N, Wakamatsu H, Oliveira JAC, Gomes ELT, De Bel EA \& Mello LEAM (1996). Neuroethological and morphological (Neo-Timm staining) correlates of limbic recruitment during the development of audiogenic kindling in seizure susceptible Wistar rats. Epilepsy Research, 26: 177-192.

17. Wahnschaffe $U$ \& Loscher W (1992). Lack of changes in seizure susceptibility during the estrous cycle in kindled rats. Epilepsy Research, 13: 199-204

18. Coimbra NC, Castro-Souza C, Segato EN, Nora JEP, Herrero CFPS, Tedeschi-Filho W \& Garcia-Cairasco N (2001). Post-ictal analgesia: involvement of opioid, serotoninergic and cholinergic mechanisms. Brain Research, 888: 314-320.

19. Chen CS, Gates GR \& Reynoldson J (1976). Effect of morphine and naloxone on priming-induced audiogenic seizures in BALB/c mice. British Journal of Pharmacology, 58: 517-520.

20. Del-Bel EA, Oliveira PR, Oliveira JAC, Mishra PK, Jobe PC \& GarciaCairasco N (1997). Anticonvulsant and proconvulsant roles of nitric oxide in experimental epilepsy models. Brazilian Journal of Medical and Biological Research, 30: 971-979.

21. Jobe PC \& Laird HE (1981). Neurotransmitter abnormalities as determinants of seizure susceptibility and intensity in the genetic models of epilepsy. Biochemical Pharmacology, 30: 3137-3144.

22. Dailey JW, Reigel CE, Mishra PK \& Jobe PC (1989). Neurobiology of seizure predisposition in genetically epilepsy-prone rats. Epilepsy Research, 3: 3-17.

23. Mülsch A, Busse R, Mordvintcev PI, Vanin AF, Nielsen EO, ScheelKrüger J \& Olesen SP (1994). Nitric oxide promotes seizure activity in kainate-treated rats. NeuroReport, 5: 2325-2328.

24. Garthwaite J (1991). Glutamate, nitric oxide and cell-cell signalling in the nervous system. Trends in Neurosciences, 14: 60-67.

25. Vincent SR \& Hope BT (1992). Neurons that say NO. Trends in Neurosciences, 15: 108-113.

26. Tutka P, Klonowski P, Dzieciuch J, Kleinrok Z \& Czuczwar S (1996). $\mathrm{N}$-nitro-L-arginine differentially affects glutamate or kainate-induced seizure. NeuroReport, 7: 1605-1608.

27. Rondouin G, Bockaert J \& Lerner-Natoli M (1993). L-Nitroarginine, an inhibitor of NO synthase, dramatically worsens limbic epilepsy in rats. NeuroReport, 4: 1187-1190.

28. Buisson A, Lakhmeche N, Verrecchia C, Plotkine M \& Boulu RG (1993). Nitric oxide: an endogenous anticonvulsant substance. NeuroReport, 4: 444-446.

29. Forstermann U, Heldt R, Knappen F \& Hertting G (1982). Potential anticonvulsive properties of prostaglandins formed in mouse brain. Brain Research, 240: 303-310.

30. Steinhauer H \& Hertting G (1981). Lowering of the convulsive threshold by non-steroidal anti-inflammatory drugs. European Journal of Pharmacology, 69: 199-203. 